\section{CHI-B: An interactive BASIC program for analyzing the power of chi-square tests}

\author{
SAN.YUN W. TSAI \\ School of Business and Public Administration, \\ California State University, Sacramento, California 95819 \\ and

\section{NORVAL F. POHL \\ College of Business Administration, Arizona State University, Tempe, Arizona 85281}

A basic problem encountered in statistical hypothesis testing is the determination of the appropriate sample size necessary to control for both Type I and Type II errors. Bradley (1976) thought sample size was particularly important in chi-square tests because of the tendency of researchers to employ such tests to confirm a null hypothesis rather than to refute it. Guenther's (1977) review of research using chi-square analyses reveals that few authors consider the issue of test power. When power is considered, authors of ten suggest skirting the issue by substituting other test procedures: Bradley (1960) recommends the use of the multinomial likelihood ratio, and Wonnacott and Wonnacott (1972) recommend forsaking testing altogether in favor of estimation.

To help practitioners calculate the sample size necessary to control for both Type I and Type II errors or, on a post hoc basis, to analyze the power of a test, a simple computer-based aid has now been developed.

Description. The program, CHI-B, is used to analyze the power of chi-square tests of goodness of fit, independence, or homogeneity. The program is designed to accommodate tests with up to $30 \mathrm{deg}$ of freedom; it automatically provides critical chi-square values when alpha is set at $.01, .05$, or .10 . Power analysis of test situations using other alpha levels can be performed, but the user must supply the critical chi-square values.

Input and Output. The terminal input may be in the form of cell frequencies or cell percentages. Output includes the value of $\lambda$ (the chi-square noncentrality factor), the effect size index (w), as defined by Cohen (1977), the probability of a Type II error $(\beta)$, the power of the test, and the sample size (n).

Computer and Language. CHI-B is written in BASIC and requires only $24 \mathrm{~K}$ core. The program is portable to nearly any size system and has been used successfully as an instructional aid running on a Nova $1220 \mathrm{CPU}$ coupled to a standard Teletype terminal.

Availability. A listing of the program, a flowchart, and operating instructions are available without cost from Norval F. Pohl, Department of Quantitative Systems, College of Business Administration, Arizona State University, Tempe, Arizona 85281.

\section{REFERENCES}

Bradley, J. V. Probability; decision; statistics. Englewood Cliffs, N.J: Prentice-Hall, 1976.

CoHEn, J. Statistical power analysis for the behavioral sciences (rev. ed.). New York: Academic Press, 1977.

Guenther, W. C. Power and sample size for approximate chisquare tests. American Statistician, 1977, 31, 83-85.

WonnacotT, T. H., \& WonnacotT, R. J. Introductory statistics for business and economics. New York: Wiley, 1972.

(Revision accepted for publication March 20, 1979.) 